\title{
Research Paper: Effectiveness of Group-based Ac- ceptance and Commitment Therapy vs Group-based Cognitive-behavioral Therapy in the Psychological Hardiness of Single Mothers
}

\author{
Hadi Motamedi ${ }^{1}$ (D), Abdolvahhab Samavi ${ }^{*}$ (D) Reza Fallahchai $^{3}$ (iD
}

1. Department of Counseling, Faculty of Humanities, University of Hormozgan, Bandar Abbas, Iran.

2. Department of Educational Sciences, Faculty of Humanities, Research Center of Educational and Behavioral Sciences, University of Hormozgan, Bandar Abbas, Iran

3. Department of Psychology, Faculty of Humanities, University of Hormozgan, Bandar Abbas, Iran.

\begin{tabular}{|c|c|}
\hline $\begin{array}{l}\text { Use your device to scan } \\
\text { and read the article online }\end{array}$ & Citation Motamedi H, Samavi A, Fallahchai R. Effectiveness of Group-based Acceptance and Commitment Therapy vs \\
\hline 口ifing & $\begin{array}{l}\text { Group-based Cognitive-behavioral Therapy in the Psychological Hardiness of Single Mothers. Journal of Research \& Health. } \\
\text { 2020; 10(6):393-402. http://dx.doi.org/10.32598/JRH.10.6.1602.2 }\end{array}$ \\
\hline 口4 & http://dx.doi.org/10.32598/JRH.10.6.1602.2 \\
\hline
\end{tabular}

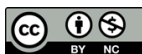

Article info:

Received: 30 Mar 2019

Accepted: 15 Jul 2019

Publish: 01 Nov 2020

\section{Keywords:}

Acceptance and Commitment Therapy, Cognitive-behavioral Therapy, Resilience, Singleparent family, Women

\section{ABSTRACT}

Background: Hardiness as a fundamental element of control plays a constructive role in coping with stress and moderates the effects of stress. This study aimed to compare the effectiveness of group-based Acceptance and Commitment Therapy (ACT) and group-based Cognitivebehavioral Therapy (CBT)in the psychological hardiness of single mothers.

Methods: The research was conducted using a quasi-experimental pretest-posttest design with control group. Also, the statistical population included all female-headed families in the region 16 of Tehran. From women with low scores in the Ahvaz psychological hardiness questionnaire, 45 women were randomly selected and assigned into three groups: two experimental and one control group. The acceptance and commitment and cognitive-behavioral therapies were implemented in the first and second experimental groups, respectively; the control group did not receive any intervention. The experimental groups received nine training sessions. Then, the study hypotheses were tested using the 1-way analysis of covariance.

Results: Both interventions effectively increased the psychological hardiness in the single mothers, but no significant difference was found between the two intervention groups $(\mathrm{P}=0.38)$.

Conclusion: According to the results, it is possible to increase the psychological hardiness of the single mothers by group-based acceptance and commitment therapy and group-based cognitivebehavioral therapy.

\section{* Corresponding Author:}

Abdolvahab Samavi, PhD.

Address: Department of Educational Sciences, Faculty of Humanities, Research Center of Educational and Behavioral Sciences, University of Hormozgan, Bandar Abbas, Iran.

Phone: +98 (917) 7609872

E-mail:wahab.samavi@gmail.co 


\section{Introduction}

any social problems, such as divorce, addiction, imprisonment, $\mathbf{M}$ and the death of the spouse, could change the structure of the family. The change of the family structure consequently increases the number of single-parent families or women's house supervision, around the world [1]. An unexpected supervision transition from husband to wife leads to a series of insecurities and the duplication of duties, including losing income, child-rearing, and playing a dual role (parenthood) for women. These duties negatively affect the physical and mental health and the life satisfaction of the women and cause new psychological problems [2]. Cheeseman, Ferguson, and Cohen [3] suggest that stressful life events can initiate and exacerbate psychological disorders and reduce the effectiveness of single mothers [4].

Evidence reveals that psychological stress is related to diseases. Based on the Selye stress theory, Kobasa has identified factors that moderate the negative effects of stress. He found that people who experience a high degree of stress without illness had a different personality structure from those who are in a stressful state. Kobasa introduced this personality trait in a structure called hardiness [5]. Psychological hardiness is a personality trait that acts as a source of resistance and protection shield in dealing with stressful life events. This character is a combination of beliefs about yourself and the world and is made up of three components: commitment, control, and challenge. Simultaneously, it is a unitary set composed of the harmonious operation of these three components [6]. Hardiness is a fundamental element of control and allows an individual to imagine and access a list of strategies and develop an optimistic view of stress [7]. Some studies show that high-hardy individuals are less likely to suffer from physical or psychological impairments in response to stress, compared with low-hardy individuals $[8,9]$.

Although psychological hardiness significantly overlaps with concepts, such as resiliency and coping strategies, it is generally a different construct. Studies emphasize that resilience occurs mainly as a psychological consequence when people experience stressful situations as opportunities for growth. Psychological hardiness is a way to achieve resilience and increases the resilience of individuals in different situations [10]. On the other hand, psychological hardiness differs from coping strategies. Primarily, hardiness is a broader concept considered as a kind of lifestyle that includes the person's overall vision of the world and the basic approach to coping with life situations, shapes a part of the individual's self-concept, and contributes to the overall growth process of personality. However, coping strategies are exclusive strategies that can act as a stress moderator, just in stressful situations [11]. The distinction between these structures is beneficial because many studies are considered the coping styles, resilience, and psychological hardiness as the same variables, while the same conceptual process is not necessarily considered. Hence, the effectiveness of educational and therapeutic interventions in psychological hardiness can be regarded as a relatively new research trend.

Despite more than 30 years of research on hardiness, some aspects of this psychological structure remain unanswered. On one hand, hardiness is regarded as a personality orientation supported by the general theory of personality traits [12]. Also, some studies point to the flexible nature of this structure. For example, Maddi et al. [13] have considered hardiness as a cognitive-emotional variable consisted of three interdependent attitudes, namely, commitment, control, and challenge. These attitudes are learned early in life and can be promoted in adulthood, through educational interventions. Maddi et al. [14] confirmed the effectiveness of hardiness training in students and working adults. However, the training programs differ in terms of complexity, from a simple self-training model to a more complete and complex approach, which includes the training of factors influencing healthy and unhealthy stress responses [15]. Among the interventions used to enhance psychological hardiness, we can refer to Cognitive-behavioral Therapy (CBT) and Acceptance and Commitment Therapy (ACT).

CBT is one of the approaches used to improve a wide range of psychological issues. This approach emphasizes the connection between thoughts, feelings, and behavior. Also, it is believed that individuals can counter psychological pressures by rebuilding their thoughts. In this approach, people are encouraged to experience better feelings and behave more appropriately, based on identifying and challenging their negative thoughts and cognitive distortions and resuming their thoughts [16].

Researche has shown the effectiveness of the CBT in bearing troubles through psychological hardiness [17], the mental health and psychological hardiness of infertile women [18], general self-efficacy and psychological hardiness in students [19], personal resilience [20], the resilience and self-esteem of adolescents with depressive symptoms [21], the resilience and psychological stress of battered women [22], the anxiety and resilience of postmenopausal 
women [23], life quality and ability to tolerate chaos in women [24], and the life quality and psychological wellbeing of women in single-parent families [25].

Previous studies have shown that CBT can greatly increase psychological hardiness. Consistent with the study of Maddi et al. [14], evidence refers to the effectiveness of educational and therapeutic interventions in hardiness structure and its variability. A review of studies showed that the study samples were mostly selected from those who were to some extent engaged with the certain sources of stress, such as infertility, depression, and marital infidelity. However, single mothers are not specifically involved with the specific sources of stress and psychological distress, compare with other vulnerable groups. Generally, living conditions with continuous stress reveals the need to upgrade the psychological stress-reducing skills and psychosocial properties in this group. Contrary to previous studies, the current study has not identified the intervention in hardiness as a coping strategy to deal with a specific stress source, but as a general strategy for application in the daily life of this group of women.

ACT is another intervention method, the effectiveness of which has been studied on psychological hardiness, in this study. This intervention is a functional contextbased one based on the theory of the relationship framework. In this approach, it is believed that human suffering derives from psychological inflexibility, which is reinforced by cognitive merging and the avoidance of experience. In this way, individuals try to avoid or alter their exposure to many emotions, feelings, or disturbing thoughts. While these efforts are ineffective and contradictory, individuals tend to exacerbate feelings, emotions, and thoughts, which they try to avoid. The goal of ACT is psychological flexibility, which is created through the six processes of acceptance, diffusion, self as a context, contact with the present moment, values, and committed action. Psychological flexibility means that people can live in the present instead of drowning in the past and future; identify their values and goals; and act according to values and goals instead of avoiding thoughts, feelings, and memories [26, 27].

A review of studies shows that a few research are conducted about the effectiveness of ACT in psychological hardiness; this study is one of the few studies conducted in this regard. In other scopes, studies showed that ACT increased self-efficacy, perceived stress, and resilience [28]; improved quality of life and psychologically empowered the single mothers [29]; improved psychological symptoms, coping styles, and quality of life in diabetic patients [30]; and increased the mental health, quality of life, and self-care behaviors [31]. A look at the dependent variables of the mentioned studies shows that studies have not directly studied the effectiveness of this approach in hardiness. Besides, fewer studies have considered ACT as an intervention to improve stress moderating strategies, in single mothers as a vulnerable group.

The effective components of ACT are the reason for choosing this approach as one of the effective interventions in psychological hardiness. This approach employs a range of educational experiences to help the person to become open, informed, and active in terms of personality, and ultimately develop a kind of feature called psychosocial flexibility. Psychological flexibility is defined as the ability to contact the moment as a self-conscious person and the change or insistence on behavior when pursuing valuable goals [32]. Hence, this approach can be effective in using these features and ultimately help a person to deal more effectively with stress.

Based on the aforementioned effectiveness of CBT and $\mathrm{ACT}$ in psychological hardiness, the present study investigated the effectiveness of these approaches in increasing psychological hardiness. Besides, this study aimed to compare the effectiveness of these two approaches. Although CBT and ACT are overlapped in some aspects and both focus on cognition, the differences between these two approaches lead to the different mechanisms of effectiveness. Contrary to CBT, the ACT therapist does not attempt to correct or eliminate the negative thoughts or feelings of the clients but encourages them to accept these feelings and simultaneously creates a commitment in people to the values that are identified and accepted by them [32]. While CBT is the second wave of cognitive therapies, ACT belongs to the third wave of cognitive therapies.

Unlike CBT, ACT focuses on accepting problems and dealing with them in a nonjudgmental manner, without any attempt to change behavior or cognition. It is anticipated that the different mechanisms of the effectiveness of these approaches have useful implications in the proposing and implementing of the approaches as the selective intervention in the psychological hardiness of single mothers. Hence, it could be challenging and useful to compare them and their effectiveness. Moreover, according to the Statistics Center of Iran [33], the percentage of single mothers raised from 9.46, in 2006 , to 12.7 , in 2016, indicating a significant increase in this group. A considerable number of the single mothers are sponsored by social support organizations, and some of them live independently. Their empowerment and selfsufficiency have been considered because of the great 
Table 1. Description of the ACT-based training sessions

\begin{tabular}{|c|c|c|c|}
\hline Sessions & Aims & Activities & Assignments \\
\hline 1 & $\begin{array}{l}\text { The establishment of thera- } \\
\text { peutic relationship, intro- } \\
\text { ducing the research sub- } \\
\text { ject, and pretest }\end{array}$ & $\begin{array}{l}\text { Introduction and familiarity; the expression of re- } \\
\text { search goals, research process, the number of ses- } \\
\text { sions, and group rules; and pretest implementation }\end{array}$ & $\begin{array}{l}\text { Describing their goals of participating in } \\
\text { the research by the participants }\end{array}$ \\
\hline 2 & $\begin{array}{l}\text { The introduction of hardi- } \\
\text { ness to the experimental } \\
\text { group }\end{array}$ & $\begin{array}{l}\text { Reviewing the assignments of the previous ses- } \\
\text { sion and discussing about the aims of the partici- } \\
\text { pants, providing explanations on the hardiness } \\
\text { and its role in life }\end{array}$ & $\begin{array}{l}\text { Identifying the hardiness effects in per- } \\
\text { sonal and social life by participants }\end{array}$ \\
\hline 3 & $\begin{array}{l}\text { The review of inefficient } \\
\text { control strategies and the } \\
\text { state of "creative hopeless- } \\
\text { ness" (The state is creative } \\
\text { because entirely new strat- } \\
\text { egies can be developed, } \\
\text { without using the previous } \\
\text { rules governing their be- } \\
\text { havior) }\end{array}$ & $\begin{array}{l}\text { Reviewing the assignments of the previous ses- } \\
\text { sion, reviewing the control strategies used by } \\
\text { individuals to deal with the problems and exam- } \\
\text { ining the effectiveness and inefficiency of them, } \\
\text { assisting participants to identify the futility of } \\
\text { control strategies, using the metaphor of the well }\end{array}$ & $\begin{array}{l}\text { Recognizing the control strategies and } \\
\text { their impact on personal and social life }\end{array}$ \\
\hline 4 & $\begin{array}{l}\text { Mindfulness and accep- } \\
\text { tance training }\end{array}$ & $\begin{array}{l}\text { Reviewing the assignments of the previous ses- } \\
\text { sion and discussing the futility of the control } \\
\text { strategies, explaining about avoiding painful ex- } \\
\text { periences and its consequences, introducing the } \\
\text { mindfulness and acceptance, introducing the } \\
\text { steps of acceptance, practicing the acceptance of } \\
\text { thoughts and feelings }\end{array}$ & $\begin{array}{l}\text { Implementing mindfulness exercises } \\
\text { during the week and studying their im- } \\
\text { pact on personal and social life }\end{array}$ \\
\hline
\end{tabular}

$5 \quad$ Cognitive defusion training

6 Self-known as "self-as-context"
Explaining cognitive fusion and expressing the relationship between emotions, cognitive functions and observable behavior, cognitive defusion training and distance from thoughts, observing thoughts without judgment, action independence of subjective experiences using train metaphor

Reviewing the assignments of the previous session and examining the effect of cognitive defusion training in the participants' lives; explaining the role, context, and types of self; moving towards a valuable life with a receptive and observer self, using the metaphor of chess board
Implementing cognitive defusion exercises during the week and studying their impact on personal and social life
Reviewing the assignments of the previous sesValues: discovering what sion, discussing the effects of observing thoughts is the most important to oneself Committed action in the lives of participants, explaining the concept of values, motivating to change, and empowering client for better life

Reviewing the assignments of the previous session and discussing about the values and barriers to action based on them, creating flexible behavioral patterns consistent with values, creating committed action in line with goals and values, and passing the barriers using the metaphor of passengers on the bus

Reviewing the assignments of the previous session and discussing the consequences of action based on values, reviewing constructive changes during the training course and teaching how to consolidate them, presenting a summary of treatment sessions and receiving feedback from participants, and performing posttests and completing the training sessions
Summarizing the sessions, performing posttest
Practicing the awareness of different feelings and separating from subjective content ones, examining their effects in personal and social life

Identifying the values and prioritizing them in the ten areas: family, marriage, friendship, occupation, education and personal growth, recreation and entertainment, spirituality, social life, environment, nature, and health

Identifying and implementing behavioral plans in accordance with values and examining their impact on personal and social life 
number of these women referring to social support organizations. However, economic empowerment is more considered and psychological empowerment has received little attention.

Psychological empowerment aimed to simultaneously address psychological variables, including self-reliance, resistance, and resilience along with economic empowerment. Psychological hardiness is one of the variables that play an important role in the resilience of these women; this variable leads to psychological, overall, and permanent empowerment. Therefore, this research has sought to improve psychological hardiness through CBT and ACT. It seems these interventions are not included in social support organizations' programs. Therefore, the results of this study will be useful for all governmental and nongovernmental organizations associated with single mothers. Accordingly, this study aimed to compare the effectiveness of group-based CBT and ACT in increasing the psychological hardiness of single mothers.

\section{Methods}

\section{Study design}

The statistical population of this research included all single mothers under the protection of the Imam Khomeini Relief Committee of Tehran, in region 16. A convenience sampling method was used, considering the number of single mothers who were referred to the committee for counseling and cooperated to attend the training sessions, the ease of notifying them about the training sessions, and organizing the training sessions. The women who were supported in district 16 responded to the questionnaire. Thereby, 45 women who received low scores on the questionnaire were randomly assigned into three groups, including two experimental and one control group. Subsequently, each of the experimental groups received CBT or ACT for nine sessions of 1.5 hours (Tables 1 and 2). The control group did not receive any training. In the pretest and posttest, the psychological hardiness questionnaire was distributed among the participants of the three groups. Regarding the research ethics, the control group was also trained, after the completion of the research. The inclusion criteria were the score of lower than the average on the hardiness questionnaire, the age range of 30 to 50 years, being the head of the family, supported by the Relief Committee, and having a minimum education of the fifth degree of elementary school. Also, the exclusion criteria were the diagnosis of clinical disorders or severe physical illness, reluctance to continue the treatment, the long-term use of antipsychotics drugs, being absent in more than one session, and incompleted questionnaire.

\section{Ethical issues}

The informed consent was obtained from the participants to enter the research. Moreover, the participants were informed about the method of implementation, the purpose of the research, the possible harms and benefits, and the nature and duration of the research. Participants were announced that they could withdraw the research at any time. Also, participants were informed that their information will remain confidential and not be disclosed.

\section{Measures}

The Ahvaz psychological hardiness questionnaire was used to collect the data. This questionnaire was developed by Kiamarsi [34]. This scale consists of 27 questions scored on a 4-option Likert scale (from never $=0$ to most of the time=3). Also, the questions 6, 7, 10, 13, 17, and 21 are reverse-scored. The score range of the scale is 0 to 81 ; a higher score indicates a higher psychological hardiness. The reliability of this questionnaire was reported as 0.84 , using the Cronbach alpha coefficient method. The concurrent validity of this scale with the anxiety scale, the Ahvaz depression scale, and the Maslow self-efficacy scale was $0.65,0.67$ and 0.62 , respectively, indicating significant coefficients [34]. In the current study, the internal consistency of the questionnaire was 0.77 , using the Cronbach alpha.

\section{Results}

The descriptive statistics in the form of mean and standard deviations were employed to describe the dependent variable, also, the 1-way analysis of covariance was used to test the hypothesis of the research. A total number of 45 single mothers with the age range of 28 to 49 years participated in this study; they were sponsored by the Relief Committee. The mean ages of the ACT, CBT, and control groups were 37,41 , and 40 years, respectively. Table 3 presents the mean and standard deviation of the hardiness scores in three study groups.

As previously mentioned, the 1-way analysis of covariance was used to test the research hypothesis and compare the effects of ACT and CBT on hardiness. Also, the test assumptions, including the homogeneity of variances and the normality were checked, before the covariance analysis. According to the result of the Kolmogorov-Smirnov test, the value of $\mathrm{Z}$ was 0.117 , and the $\mathrm{P}$-value was 0.14 , which confirmed the normality of data. Also, the Levine test was used to check the homogeneity of variances. The $\mathrm{P}$-value for the hardiness variable was 0.07 and the F-value was 1.126 , which confirmed the homogeneity of variances. Table 4 presents the results of covariance analysis. 
Table 2. Description of Cognitive-Behavioral Training Sessions

\begin{tabular}{|c|c|c|c|}
\hline Sessions & Aims & Activities & Assignments \\
\hline 1 & $\begin{array}{l}\text { The establishment of thera- } \\
\text { peutic relationship, intro- } \\
\text { ducing the research subject } \\
\text { to participants, and pretest }\end{array}$ & $\begin{array}{l}\text { Introduction and familiarity; the expression of research } \\
\text { goals, research process, the number of sessions, and } \\
\text { group rules; pretest implementation }\end{array}$ & $\begin{array}{l}\text { Describing their goals of partici- } \\
\text { pating in the research by the par- } \\
\text { ticipants }\end{array}$ \\
\hline 2 & Self-awareness & $\begin{array}{l}\text { Reviewing the previous session assignments; discus- } \\
\text { sion about the goals of the participants attending the } \\
\text { research plan; the empowerment of the members in } \\
\text { the field of self-awareness and recognize the character- } \\
\text { istics, needs, desires, goals, values, and identity }\end{array}$ & $\begin{array}{l}\text { Identify and note positive and } \\
\text { negative features, needs, desires, } \\
\text { and values }\end{array}$ \\
\hline
\end{tabular}

Reviewing the previous session assignments, discussion about the problems of the participants on the The identification and path of self-awareness and reviewing the needs and change of cognitive distor- desires; introducing the relationship between thought tion feeling, and behavior and familiarity with spontaneous tive distortions

Reviewing the previous session assignments, discussion about identified cognitive distortion and its effect

4

Familiarity with the concept of attribution on the thoughts, feelings and behavior concept in the life of clients, knowing the attribution and recognizing the causes of misinterpretation and training technique to change attributions
Diary events, thoughts, and feelings; following them, and identify the cognitive distortions
Recognizing the attributions of bad events in life and attempting to change wrong attributions
Reviewing the previous session assignments; discussion about the effect of attribution change in behavior thoughts, and feelings; training the problem-solving skills, including the definition of the problem, alternative solutions, evaluation solutions, selection and the implementation of the selected solution, and evaluating the applied solution

Reviewing the assignments of previous session and discussion about the impact of applying the problemsolving skills in personal and social life, the definition of the communication and its elements, introducing the effective communication skills and its features, training effective negotiation styles and solving the controversy
Check one of the problems faced by client and applying problem solving skill about it

Practice communication skill during the week and reviewing its consequences
Reviewing the assignments of previous session, discus sion about the impact of applying effective communication practices in personal and social life, introducing the assertive behavior, practical activities and role playing to learn communication skill
Practice assertive behavior during the week and reviewing its consequences behavior

Reviewing the constructive changes and consolidating them

Summarizing the sessions and performing the posttest
Reviewing the assignments of previous session, discussion about the impact of applying the assertive behavior in social and personal life, reviewing the constructive changes during the treatment sessions, highlighting the success of talk about the consolidation of changes

Providing a summary of the training sessions and an overview of trained skills, discussion about the positive points and the weakness of therapist, training plan and get feedback from the participants, and performing the posttest 
Table 3. Mean \pm SD of hardiness variable, in pretest and posttest, by research group

\begin{tabular}{lccc}
\hline \multirow{2}{*}{ Variable } & Groups & \multicolumn{2}{c}{ Mean \pm SD } \\
\cline { 3 - 4 } & & Pre-test & Post-test \\
\hline \multirow{2}{*}{ Hardiness } & Control & $36.40 \pm 8.02$ & $36.33 \pm 7.49$ \\
& ACT & $35.86 \pm 5.60$ & $48.66 \pm 8.32$ \\
& CBT & $38.60 \pm 10.11$ & $52.40 \pm 7.01$ \\
\hline
\end{tabular}

Table 4. Results of the analysis of covariance showing the effects of ACT and CBT on hardiness

\begin{tabular}{ccccccc}
\hline Sources & SS & DF & MS & F & P & Eta \\
\hline Corrected model & 3573.57 & 3 & 1191.19 & 49.05 & 0.001 & 0.78 \\
\hline Group & 1864.06 & 2 & 932.03 & 38.38 & 0.001 & 0.65 \\
Error & 995.62 & 41 & 24.28 & & & \\
Total & 98963 & 45 & & & & \\
Corrected total & 4569.20 & 44 & & & & \\
\hline
\end{tabular}

MRE

Table 5. Pairwise comparisons of the posttest hardiness scores of three groups by the bonferroni post hoc test

\begin{tabular}{ccccc}
\hline Variable & Factor (i) & Factor $(\mathbf{j})$ & Mean \pm SD & P \\
\hline \multirow{2}{*}{ Hardiness } & Control & ACT & $12.71 \pm 1.81$ & 0.001 \\
& & CBT & $14.47 \pm 1.80$ & 0.001 \\
& ACT & CBT & $1.75 \pm 1.81$ & 0.38 \\
\hline
\end{tabular}

unt

The results of covariance analysis by controlling the effect of pretest reveals a significant difference between the three groups (Table 4). The Bonferroni post hoc test was used to compare the hardiness scores of the three groups in the posttest; Table 5 presents the results.

The results of the Bonferroni post hoc test showed a significant difference in the psychological hardiness between the control group and the ACT and CBT groups $(\mathrm{P}<0.001)$. Therefore, ACT and CBT significantly increased the psychological hardiness of the single mothers, compared with the control group. However, the posttest scores did not significantly differ between the two methods of intervention.

\section{Discussion}

The results of this study showed that ACT is effective in increasing the psychological hardiness of single mothers. The results of this study are consistent with the studies of Mohammadi et al. [29], Behrouz et al. [30], and Esmi [31]. Therefore, ACT includes components that improve psychological hardiness by training. For instance, ACT emphasizes the psychological flexibility, which is one of the components of hardiness [32]. When people learn this skill, they show more flexibility, therefore, their control increase over their living conditions. Besides, commitment to goals and values is another topic emphasized in ACT. When people learn to commit to the goals, they assign for themselves, directly act in line with their values, and are more responsible. 
The findings of this study on the effectiveness of ACT in psychological hardiness can be explained in two ways. First, past studies have shown that this approach changes the psychological context, where individuals experience their thoughts and feelings, rather than directly change them. Adhering to the Adlerian view of hardiness [11, 35], the ACT approach is primarily sought to change the person's overall view of the world and coping with life situations. Second, the processes designed to enhance psychological flexibility can address a wide range of psychological and behavioral problems. Thus, with improving psychological flexibility, ACT ultimately increases the hardiness.

Also, findings showed that CBT increases the psychological hardiness of single mothers. This finding is consistent with the studies of Sadeghi [22], Mousavi [25], Behzadipour [36], and Mosalanejad et al. [18]. The cognitive-behavioral approach aimed to change the distorted and irrational beliefs and thoughts. The distorted thoughts affect the individuals' feelings, and consequently, their behaviors. This approach includes techniques, such as the problem-solving approach to deal with turbulent issues. In the problem-solving technique, people are trained to deal with problems, rather than avoidance or excitement. Simultaneously, they will not escape the problems, nor will they engage emotionally, because both approaches are destructive and ineffective. In a problem-oriented approach, people find problems as just solvable problems and challenge these problems. By training this technique, people learn to challenge. Moreover, challenge is one of the components of psychological hardiness.

Another important issue in explaining the findings is that CBT reduces psychological distress in individuals. Previous studies have shown a relationship between hardiness and the increased levels of mental health [18]. This means that as much as the level of psychological distress is reduced, the hardiness is increased, thus, individuals become more resistant to stress, anxiety, and depression.

Troy et al. [37] have suggested that the reassessment of the meaning of a difficult situation leads to a more positive outlook and the more adaptive responses. Therefore, the cognitive nature of the cognitive-behavioral approach leads to the increased psychological hardiness. The use of cognitive-behavioral approach increases psychological hardiness, because hardiness is reinforced as an output of treatment in individuals. Although CBT usually focuses on the treatment of symptoms, the other treatment outcomes, such as psychological hardiness and resilience should be considered. The present study clearly showed that the cognitive-behavioral approach could potentially affect the other consequences of treatmnt, such as hardiness.

The findings showed no significant difference between the effectiveness of the two interventions in psychological hardiness. One possible explanation for the lack of significant difference between these two approaches can be given with regard to the effectiveness of these two approaches over time. Although there is no significant difference between the two approaches in the short-term, the long-term differences are predicted to be in the favor of ACT, considering the more general and wider nature of this approach. Compared with CBT, ACT has shown a more lasting effect on the cognitive, behavioral, and emotional outcomes, in long-time [38, 39].

\section{Conclusion}

Totally, the results of this study showed that ACT and CBT increase the hardiness of single mothers. Given the role of hardiness in the quality of life, the use of these trainings is recommended to specialists in this area.

There were some limitations in this study, including low socioeconomic levels of participants, so that financial and economic issues reduced incentives to attend training sessions. Also, the convenience sampling method and the use of self-report questionnaires limited the results of this study. Likewise, this study included no follow-up phase. It is suggested to compare the short-term and long-term effectiveness of these two approaches, in the future studies.

\section{Ethical Considerations}

\section{Compliance with ethical guidelines}

The research plan was approved by the Ethics Committee of the University of Hormozgan (Code: 10764, on November 2, 2018).

\section{Funding}

This article is extracted from the PhD. thesis of the first author, Department of Counseling, Faculty of Humanities, University of Hormozgan, Bandar Abbas.

\section{Authors' contributions}

All authors equally contributed to preparing this article. 


\section{Conflict of interest}

The authors decleared no conflicts of interest.

\section{Acknowledgments}

We thank the staff of Imam Khomeini Relief Committee, in particular the staff of the Tehran Province and district 16, who sincerely assisted us for the implementation of this study. Also, we are thankful to the participants of this research.

\section{References}

[1] Fahey T, Keilthy P, Polek E. Family relationships and family well-being: A study of the families of nine year-olds in Ireland. Dublin: Published by University College Dublin and the Family Support Agency; 2012. https://researchrepository.ucd.ie/handle/10197/5102

[2] Herbst CM. Footloose and fancy free? Two decades of single mothers' subjective well-being. Soc Serv Rev. 2012; 86(2):189-222. [DOI:10.1086/666390]

[3] Cheeseman S, Ferguson C, Cohen L. The experience of single mothers: Community and other external influences relating to resilience. Aust Community Psychol. 2011; 23(2): 32-49. https:// www.semanticscholar.org/paper/The-Experience-of-SingleMothers\%3A-Community-and-to-Cheeseman-Ferguson/ e61f08390676329265acc20ff59ed120394be19b

[4] Crosier T, Butterworth P, Rodgers B. Mental health problems among single and partnered mothers. Soc Psychiatry Psychiatr Epidemiol. 2007; 42(1):6-13. [DOI:10.1007/s00127-006-0125-4] [PMID]

[5] Kiamarsi A, Najarian B, Mehrabizadehhonarmand M. [Hardiness scale measurement structure and validation (Persian)]. J Psychol. 1998; 5(3-4):271-85. https://www.sid.ir/fa/journal/ ViewPaper.aspx?ID=74971

[6] Kobasa SC. Stressful life events, personality, and health: An inquiry into hardiness. J Pers Soc Psychol. 1979; 37(1):1-11. [DOI:10.1037/0022-3514.37.1.1] [PMID]

[7] Roghanchi M. [The relationship between religious oriantatin and psychological health in Kermanshah University students (Persian)] [PhD. dissertation]. Kermanshah: University of Social Welfare and Rehabilitation Sciences; 2005

[8] Sharifi KH, Arizi Samani SH, Namdari K. [A study of the relationship between family functioning and psychologhical Hardiness of high school students in Isfahan (Persian)]. Daneshvar Raftar. 2005; 12(10):85-94. https://www.sid.ir/fa/Journal/ ViewPaper.aspx?id=29898

[9] Brannon L, Feist J. Health psychology: An introduction to behavior and health. $3^{\text {th }}$ ed. California: Brooks/Cole Publishing Company; 1997. https://books.google.com/books/about/ Health_Psychology.html?id=cKlpAAAAMAAJ
[10] Southwick SM, Bonanno GA, Masten AS, Panter-Brick C, Yehuda R. Resilience definitions, theory, and challenges: Interdisciplinary perspectives. Eur J Psychotraumatol. 2014; 5(1):1-14. [DOI:10.3402/ejpt.v5.25338] [PMID] [PMCID]

[11] Bartone PT, Hystad SW, Eid J, Brevik JI. Psychological hardiness and coping style as risk/resilience factors for alcohol abuse. Mil Med. 2012; 177(5):517-24. [DOI:10.7205/MILMEDD-11-00200] [PMID]

[12] Maddi SR, Matthews MD, Kelly DR, Villarreal BJ, Gundersen KK, Savino SC. The continuing role of hardiness and grit on performance and retention in West Point cadets. Mil Psychol. 2017; 29(5):355-8. [DOI:10.1037/mil0000145]

[13] Maddi S. Hardiness is negatively related to gambling. OALib J. 2016; 3(08). [DOI:10.4236/oalib.1102250]

[14] Maddi SR, Harvey RH, Khoshaba DM, Fazel M, Resurreccion $\mathrm{N}$. The personality construct of hardiness, IV: Expressed in positive cognitions and emotions concerning oneself and developmentally relevant activities. J Humanist Psychol. 2009; 49(3):292-305. [DOI:10.1177/0022167809331860]

[15] Hystad SW, Olsen OK, Espevik R, Säfvenbom R. On the stability of psychological hardiness: A three-year longitudinal study. Mil Psychol. 2015; 27(3):155-68. [DOI:10.1037/mil0000069]

[16] Prochasca JA, Norcras JO. Psychotherapy theories. [Mohammadi SH, Persian Trans]. Tehran: Roshd; 2008.

[17] Mahfud A, Jafar M, Sunawan S. Dampak Konseling Kelompok Cognitive Behavior Therapy dengan Teknik Stress Inoculation Training terhadap Toleransi Distres Akademik melalui Hardiness. JUBK. 2017; 6(1):94-100. https://journal.unnes.ac.id/sju/ index.php/jubk/article/view/17447

[18] Mosalanejad L, Khodabakshi Koolaee A, Jamali S. Effect of cognitive behavioral therapy in mental health and hardiness of infertile women receiving Assisted Reproductive Therapy (ART). Iran J Reprod Med. 2012; 10(5):483-8. [PMCID]

[19] Molla Jafar H, Salabifard S, Mousavi SM, Sobhani Z. The effectiveness of group training of CBT-based stress management on anxiety, psychological hardiness and general self-efficacy among university students. Glob J Health Sci. 2015; 8(6):47-54. [DOI:10.5539/gjhs.v8n6p47] [PMID] [PMCID]

[20] Deblingera E, Pollioa E, Runyonb MK, Steer RA. Improvements in personal resiliency among youth who have completed trauma-focused cognitive behavioral therapy A preliminary examination. Child Abuse Negl. 2017; (65):132-9. [DOI:10.1016/j. chiabu.2016.12.014] [PMID]

[21] Beygi A, Najafi M, Mohammadyfar MA, Abdollahi A. [The effectiveness of positive cognitive behavioral therapy on selfesteem and resilience among the adolescents with depression signs (Persian)]. RBS. 2018; 16(1):47-53. https://rbs.mui.ac.ir/ article-1-581-en.html

[22] Sadeghi E. [Comparison of the effectiveness of Cognitive-behavioral Therapy and combining cognitive behavioral therapy and cognitive therapy on resilience and psychosocial containment of felicitous women (Persian)] [PhD. dissertation]. Tehran: Payam Noor University center; 2009.

[23] Charmchi N, Asgari P, Hafezi F, Makvandi B, BakhtiarPour S. [The effect of "cognitive behavior therapy" in method group on anxiety and psychological resilience of menopausal women (Persian)]. Iran Nurs Sci Assoc. 2016; 5(5):15-22. [DOI:10.21859/ jhpm-06013] 
[24] Noorbakhsh S, Ayadi N, Fayazi M, Sadri E. [Effectiveness of happiness training program based on fordyce cognitive behavioral theory on quality of life and ability to tolerate disorders of women with physical-motor disabilities (Persian)]. IJRN. 2018; 4(2):35-43 http://ijm.ir/browse.php?a_id=305\&sid=1\&slc_lang=fa

[25] Mousavi SS. [Effectiveness of Cognitive-behavioral Therapy on quality of life and psychological well-being of unmarried women under the auspices of the Department of Welfare of Gachsaran (Persian)]. Research project of the Department of Welfare of Gachsaran; 2012.

[26] Hayes SC, Strosahl K, Wilson KG, Bissett RT, Pistorello J, Toarmino $\mathrm{D}$, et al. Measuring experiential avoidance: A preliminary test of a working model. Psychol Rec. 2004; 54:553-78. [DOI:10.1007/BF03395492]

[27] Hayes SC, Strosahl KD. A practical guide to Acceptance and Commitment Therapy. New York: Springer science and business media Inc; 2010

[28] Mohammadi Khashouei M, Ghorbani M, Tabatabaei F. The effectiveness of Acceptance and Commitment Therapy (ACT) on self-efficacy, perceived stress and resiliency in type II diabetes patients. Global J of Health Sci. 2017; 9(5):18-26. [DOI:10.5539/gihs. v9n5p18]

[29] Mohammadi Z. Effectiveness of Acceptance and Commitment based Therapy on quality of life and psychological empowerment of female headed households covered by the Welfare Organization of Tehran (Persian)] [MSc. Thesis]. Tehran: Allameh Tabatabaei University; 2015.

[30] Behrouz B, Bwaly F, Heidarizadeh N, Farhadi M. [The effectiveness of acceptance and commitment-based therapy on psychological symptoms, coping styles and quality of life in type 2 diabetic patients (Persian)]. j.health. 2016; 7(2):236-53. http://healthjournal.arums.ac.ir $/$ browse.php?a_id=919\&sid=1\&slc_lang=en

[31] Esmi Z. [The effectiveness of Acceptance and Commitment Therapy (ACT) on mental health and quality of life and self-care behaviors in patients with breast Cancer (Persian)] [MSc. Thesis]. Tehran: Alzahra University; 2016.

[32] Wynne B, McHugh L, Gao W, Keegan D, Byrne K, Rowan C, et al. Acceptance and Commitment Therapy reduces psychological stress in patients with inflammatory bowel diseases. Gastroenterology. 2019; 156(4):935-45. [DOI:10.1053/j.gastro.2018.11.030] [PMID]

[33] Statistics Center of Iran. [Detailed results of the general census of population and housing 1395 total country (Persian)]. Tehran; 2016.

[34] Kiamarsi A. [Making and Validating the Scale for Psychosocial Thinking and its Relationship with Personality Type A, Self Esteem, Physical Complaints and Academic Performance in Male and Female Students of Islamic Azad University of Ahvaz. [PhD disserration]. Ahvaz. 1997 (In)

[35] Hays NP, Bathalon GP, McCrory MA, Roubenoff R, Lipman R, Roberts SB. Eating behavior correlates of adult weight gain and obesity in healthy women aged 55-65 y. Am J Clin Nut. 2002; 75(3):476-83. [DOI:10.1093/ajcn/75.3.476] [PMID]

[36] Behzadipour S. [Comparison of the effectiveness of Cognitivebehavioral Therapy on stress management and cognitive-based mindfulness therapy on quality of life and coping strategies in women with breast cancer (Persian)] [PhD. disserration]. Tehran Islamic Azad University tehran Central Branch; 2013.
[37] Troy AS, Wilhelm FH, Shallcross AJ, Mauss IB. Seeing the silver lining: cognitive reappraisal ability moderates the relationship between stress and depressive symptoms. Emotion. 2010; 10(6):783-95. [DOI:10.1037/a0020262] [PMID] [PMCID]

[38] González-Menéndez A, Fernández P, Rodríguez F, Villagrá $\mathrm{P}$. Long-term outcomes of Acceptance and Commitment Therapy in drug-dependent female inmates: A randomized controlled trial. Int J Clin Health Psychol. 2014; 14(1):18-27. [DOI:10.1016/S1697-2600(14)70033-X]

[39] Bach P, Hayes SC, Gallop R. Long-term effects of brief Acceptance and Commitment Therapy for psychosis. Behav Modif. 2012; 36(2):165-81. [DOI:10.1177/0145445511427193] [PMID] 